\title{
Safety measures between reality and intentions among nursing students regarding needle stick injuries
}

\author{
Hanan Ramzy Ahmed Atalla* \\ Medical Surgical Nursing Department, Faculty of Nursing, Menoufia University, Egypt
}

Received: December 2, 2018

Accepted: March 10, 2019

Online Published: March 29, 2019

DOI: $10.5430 /$ cns.v7n2p87

URL: https://doi.org/10.5430/cns.v7n2p87

\begin{abstract}
Objective: The purpose of this study was to describe safety measures between reality and intentions among nursing students regarding needle stick injuries.

Methods: Research Design: descriptive study cross sectional design. Setting: The study was carried out at three setting as the following: Faculty of Nursing, Institute of Nursing, School of Nursing at Menofia University, Menofia Governorate, Egypt. Subjects: 150 student nurses were included in the study. Tools for data collection: Interviewing questionnaire comprised of two sections: Demographic information, questionnaire regarding; mechanism of a needle stick injury the nursing students if present, at which stage needle injury occurs and reasons for not reporting that injury from student's point of view, and safety injection checklist for assessing injection practices among injection providers.

Results: Majority of studied sample were female mostly injured at outpatient clinic, medical department. Injury occurred mainly during IV injection, followed by IM injection and recapping needle. The majority of studied subject perceived that the reason of injury of needle stick injury were excitement and fear of Punishment and low grade during evaluation was the most common cause for non-reporting injury of needle stick injuries. Safety Injection Checklist for assessing injection practices among injection providers; showed $18 \%$ of study group were unsatisfied practiced while $100 \%$ of 3rd group showed satisfied practice.

Conclusions: Increasing the awareness about the importance of reporting needle stick injuries is cardinal intervention to take adequate preventive measures for safety and continuous training and awareness program on injection safety to all the student nurses is a necessity for reducing the unsafe practices.
\end{abstract}

Key Words: Safety, Needle stick injuries, Nursing student

\section{INTRODUCTION}

Commonly encountered problems in the medical setting by people handling needles are needle stick and sharp object injuries (NSSIs). ${ }^{[1,2]}$ The susceptibility of nursing students to the risk of needle sticks injury are high due to lack of experience, inadequate knowledge related to handling sharp instruments; tiredness; and absence of instructional train- ing. ${ }^{[3]}$

In order to achieve learning outcomes, nursing students in an undergraduate program need to be skilled in some clinical procedures such as the administration of parenteral medication (intramuscular or intravenous). These students initially perform non-invasive procedure and as they advance in their levels, are expected to perform invasive procedures, such as

\footnotetext{
*Correspondence: Hanan Ramzy Ahmed Atalla; Email: hanan.ataaallah@nursing.menofia.edu.eg; Address: Medical Surgical Nursing Department, Faculty of Nursing, Menoufia University, Egypt.
} 
students are able to practice these procedures in clinical labs prior to performing in "the real situations" in the real-clinical setting. The prepared clinical labs setting provides a safe environment in presence of clinical instructors as the students demonstrated the practice on simulated models, these clinical procedures repeatedly practiced in the simulated setting until the student becomes competent. ${ }^{[4]}$ The National Institute for Occupational Safety and Health (NIOSH) USA defines a needle stick injury as "injuries that are caused by objects such as hypodermic needles, blood collection needles, cannula and needles used to connect parts of IV delivery systems". [5]

Occurrence of needle stick injuries among undergraduate nursing students such as removing the cap of needle and breaking ampoules are considered high risk. Thus, educational courses for nursing students should focus on reducing these risks. ${ }^{[6]}$ Improving clinical practice among undergraduate nursing students and increasing awareness of preventive measures of needle sticks injuries. Moreover, teaching programs should pointed to preventive measures of needle sticks injuries and sharp objects, among health care personnel. Also, it is a necessary to ensure reporting system of injuries among undergraduate nursing student to be routine behavior when they face in areal situation. ${ }^{[6]}$

A study of Irmak \& Baybuga ${ }^{[7]}$ had rationalized high risk of needle stick injuries among nursing and non-reporting of that injuries due to inexperience at clinical setting and lack of technical expertise, and limited knowledge about preventive measures associated with these injuries and suggested effective needle stick injury prevention measures as "the combination of engineering and the work practice controls, the use of personal protective clothing and the equipment, hepatitis B vaccinations, and signs and labels". So to improve awareness and knowledge among undergraduate nursing students educational courses should emphasize positive learning outcomes that lead to better perceptions toward safety measures. ${ }^{[3]}$

\subsection{Significance of the study}

Undergraduate nursing students were at high risk of needle stick injuries due to inadequate practical experience on handling sharp instruments in clinical settings. ${ }^{[4]}$ The occupational exposures to NSIs in the developing world are considered to be much higher that are not evenly reported, around $75 \%$ of the cases in developing countries. ${ }^{[8]}$

Its occurrence is higher than present estimates, and from here a less reporting of injury should not be considered as absence of problem. ${ }^{[9]}$ So this study was carried out to describe safety measures between reality and intentions among nursing students regarding needle stick injuries.

\section{METHODS}

\subsection{Aim}

To analyze the gap between preparation of students for handling needle stick injuries and their actions after they sustain an injury.

\subsection{Design}

Descriptive cross sectional design was used for this study.

\subsection{Setting}

This study was carried out at three settings as the following: Faculty of Nursing, Institute of Nursing, School of Nursing (which are the main sources for nursing professional personal who formally assigned to work in health care setting) at Menofia University Menofia Governorate, Egypt.

\subsection{Subjects}

A proportional allocation sample of $30 \%$ from the above mentioned setting enrolled the academic year 2017-2018 were included in the study, Menoufia governorate 174 were in second academic year nursing student from faculty of nursing, 180 were in second academic year nursing student from institute of nursing and 167 students from school of nursing, six of them incomplete the interview thus the sample size were (150 students). All of them have to practice invasive procedure as parenteral administration of medication as a part of their learning outcomes at clinical setting.

\subsection{Eligibility}

Inclusion criteria: All students of the study have to apply parenteral medication at clinical sitting. And student nurse who has injured at least once during clinical training.

Sampling selection: Non-probability purposive sampling was used.

Instrument: Two tools were used.

Tool I: Interviewing questionnaire was constructed by investigator, and it is comprised the following:

Section I - Demographic information: to assess personal characteristics of study sample, which included five items (age, sex, academic year, presence of experience, and area of clinical setting).

Section II: Interviewing questionnaire regarding: It consisted of main five parts as a) mechanism of a needle stick injury (during blood withdrawal, recapping needle, IM or IV injection), b) at which stage needle injury occurs (during use of needle, after use but before disposal, during disposal), c) reasons of injury (rush, lack of experience, lack of assistant, excitement), d) from student's point of view, reasons for not reporting injury of needle sticks (fear of stigmatization, 
lack of knowledge, heavy clinical schedule, low possibility of infection, shaming of the colleagues, and punishment and low grade during evaluation), e) and safety measures taken after a needle stick injury as washing of area with soap and water, cleaning of area with spirit swab, putting plaster on wound and screening of blood.

Tool II: The Safety Injection Checklist, adopted from Jahangiri et al. ${ }^{[10]}$ was used to assess injection practices among students. "It consists of 23 items including items on the safe injection practices taken during and after the procedure of injection, the availability of safety facilities (such as safety box), personal protective equipment (PPE) used during and after the procedure of injection, and the preventive and treatment measures taken before and after the injury". After pilot study some items were excluded as Blood test after needle stick injury (which is not done at all for students), Passing the preventive training courses of needle stick injury (which should excluded from the study), and Receiving hepatitis B vaccine in 3 doses (not performed for students) after modification total score for 20 items. Each item/question was then scored as: 0 (unsafe practice), 1 (inadequate safe practice), and 2 (completely safe practice).

Scoring system: Total score for 20 items of scale equal 40. Each item was then scored: 0 (unsafe practice), 1 (inadequate safe practice), and 2 (completely safe practice). $60 \%$ equal to 24 degree of observational checklist. Scoring less than $60 \%$ considered unsatisfactory practice while scoring more than $60 \%$ considered satisfactory practice regarding needle stick injuries.

\subsection{Validity and reliability}

Tools were tested for content validity "a measure where the actual content matches the measurement which is a logical method of measurement" by five experts in the field of Medical Surgical Nursing (two of them academic are assistant professors of medical surgical nursing and three are lecturers of medical surgical nursing all of them are supervisors with clinical instructors during clinical training of students), Faculty of Nursing, Menoufia University, and modifications were done accordingly. All tools were tested for reliability using test retest method to ascertain consistency: interviewing questionnaire regarding needle stick injuries, $r=0.84$, Safety Injection Checklist for assessing injection practices among injection providers $r=0.70$.

\subsection{Data collection}

The researcher interviewed nursing students from three different three settings as the following: Faculty of Nursing, Institute of Nursing, School of Nursing at Menofia University, Menofia Governorate, Egypt and explained the aim of

Published by Sciedu Press the study during the end of evaluation at clinical setting.

Students were distributed into subgroups and asked to fill in the interviewing questionnaire related to needle stick injuries, reasons, barriers for not reporting in the presence of researcher with clinical supervisors. It took about 25 minutes for tool one, and then Safety Injection Checklist for assessing injection practices among nursing students was done by clinical supervisors it took about 15 minutes for observing students during performing the procedure. Both tools, returned to the researcher immediately. Only students included in the study sample who had answered the questionnaires.

The tools were used in English language and for students from school of nursing researcher explained briefly what has been unclear for them. The researcher and clinical supervisors were experienced in medical surgical nursing and responsible for educating students that guaranteed that there is no misunderstanding in relation to the English language.

Data collection occurred between May 2017 and June 2017 during the second semester of academic year 2017-2018.

\section{Pilot study}

The pilot study was done on (10\%) 15 students to test the clarity and applicability of used tools. The analysis of the pilot study revealed some modifications that were considered and required for validity of the tools. So, pilot study subjects were excluded from the study.

\subsection{Ethical considerations}

Ethical approval and permission to interview students was allowed from the dean of faculty of nursing, Menofia University, manager of institute of nursing and manager of school of nursing. Informed consent forms were obtained prior to interviews and participation in the study was voluntary. Anonymity and confidentiality were ensured by not asking participant their names (each student have code number to deal statistically) and not sharing the collected information with others.

\subsection{Statistical analysis}

Data were collected, tabulated and statistically analyzed with IBM SPSS statistics 20 software statistical package data was presented using number, percentage, mean and standard deviation.

\section{RESULTS}

Table 1 showed that over half of the studied sample of the three groups were female. Regarding the clinical setting areas; around half of first group and third groups were injured in outpatient clinic setting while the second group was injured mainly at medical department. Although the least 
percentage reported from three groups were at emergency department; with no statistical significant difference.

Injury occurs mainly during IV injection, followed by IM injection and recapping needle while injuries during blood withdrawal reported least percentage with no statistical significant difference (see Table 2).
Table 3 showed that Procedures in Different Stages of Needle Use Involving Needle Stick Injuries; about half of the studied subject injured during injection for all groups than during specific procedure for first group. While after use but before disposal over half injured during recapping a needle then bending or breaking by hand before disposal for all groups.

Table 1. Socio demographic characteristics of the studied subject

\begin{tabular}{|c|c|c|c|c|c|c|c|c|}
\hline \multirow{2}{*}{ Socio demographic characteristics } & \multicolumn{2}{|c|}{$1^{\text {st }} \operatorname{group}(\mathrm{N}=50)$} & \multicolumn{2}{|c|}{$2^{\text {nd }}$ group $(N=50)$} & \multicolumn{2}{|c|}{$3^{\text {rd }}$ group $(N=50)$} & \multirow{2}{*}{$\chi^{2}$} & \multirow{2}{*}{$p$ value } \\
\hline & No & $\%$ & No & $\%$ & No & $\%$ & & \\
\hline \multicolumn{9}{|l|}{ Sex } \\
\hline Female & 28 & 56.0 & 36 & 72.0 & 35 & 70.0 & \multirow[t]{2}{*}{3.38} & \multirow[t]{2}{*}{.184} \\
\hline Male & 22 & 44.0 & 14 & 28.0 & 15 & 30.0 & & \\
\hline \multicolumn{9}{|l|}{ Area of clinical setting } \\
\hline Medicine & 12 & 24.0 & 17 & 34.0 & 11 & 22.0 & \multirow{5}{*}{9.38} & \multirow{5}{*}{.311} \\
\hline Surgery & 7 & 14.0 & 7 & 14.0 & 6 & 12.0 & & \\
\hline Emergency & 4 & 8.0 & 9 & 18.0 & 8 & 16.0 & & \\
\hline Outpatient clinic & 20 & 40.0 & 8 & 16.0 & 18 & 36.0 & & \\
\hline Orthopedic & 7 & 14.0 & 9 & 18.0 & 7 & 14.0 & & \\
\hline
\end{tabular}

Table 2. Mechanism of injury of needle sticks injury

\begin{tabular}{|c|c|c|c|c|c|c|c|c|}
\hline \multirow{2}{*}{ Variable } & \multicolumn{2}{|c|}{$1^{\text {st }}$ group $(\mathrm{N}=50)$} & \multicolumn{2}{|c|}{$2^{\text {nd }}$ group $(N=50)$} & \multicolumn{2}{|c|}{$3^{\text {rd }}$ group $(N=50)$} & \multirow{2}{*}{$\chi^{2}$} & \multirow{2}{*}{$p$-value } \\
\hline & No & $\%$ & No & $\%$ & No & $\%$ & & \\
\hline Blood withdrawal & 0 & 0 & 1 & 2 & 0 & 0 & \multirow{4}{*}{5.26} & \multirow{4}{*}{.729} \\
\hline Recapping needle & 5 & 10 & 7 & 14 & 5 & 10 & & \\
\hline IM injection & 20 & 40 & 18 & 36 & 16 & 32 & & \\
\hline IV injection & 25 & 50 & 24 & 48 & 25 & 50 & & \\
\hline
\end{tabular}

Table 3. Procedures in different stages of needle use involving needle stick injuries

\begin{tabular}{|c|c|c|c|c|c|c|c|c|}
\hline \multirow{2}{*}{ Medical characteristics } & \multicolumn{2}{|c|}{$1^{\text {st }}$ group $(\mathrm{N}=50)$} & \multicolumn{2}{|c|}{$2^{\text {nd }}$ group $(N=50)$} & \multicolumn{2}{|c|}{$3^{\text {rd }} \operatorname{group}(N=50)$} & \multirow{2}{*}{$\chi^{2}$} & \multirow{2}{*}{$p$ value } \\
\hline & No & $\%$ & No & $\%$ & No & $\%$ & & \\
\hline \multicolumn{9}{|l|}{ During use of needle } \\
\hline Drawing blood & 0 & 0.0 & 1 & 2.0 & 0 & 0.0 & \multirow{5}{*}{5.26} & \multirow{5}{*}{.729} \\
\hline Preparing injection & 5 & 10.0 & 7 & 14.0 & 5 & 10.0 & & \\
\hline Adjusting drug dose for parenteral injection & 7 & 14.0 & 9 & 18.0 & 9 & 18.0 & & \\
\hline During injection & 25 & 50.0 & 24 & 48.0 & 29 & 58.0 & & \\
\hline Doing a specific procedure & 13 & 26.0 & 9 & 18.0 & 7 & 18.0 & & \\
\hline \multicolumn{9}{|l|}{ After use but before disposal } \\
\hline Recapping a Needle & 35 & 70.0 & 34 & 68.0 & 30 & 60.0 & \multirow[t]{2}{*}{1.24} & \multirow[t]{2}{*}{.536} \\
\hline Bending or breaking by hand before disposal & 15 & 30.0 & 16 & 32.0 & 20 & 40.0 & & \\
\hline
\end{tabular}

Note. Specific procedure as (IV line, dressing, handling rash)

The majority of studied subject from all groups perceived that the Reason of Injury of Needle Stick was excitement which represent high percentage while lack of experience and rush represent lower percentage and lack of assistant nearly unfound (see Table 4).

Table 5 showed that fear of Punishment and low grade during evaluation was the most common rationale for not reporting 
injury of needle stick injuries among three groups followed by lack of knowledge about reporting the injuries. Other variables as; Heavy clinical work load, Low risk of infection in the injured site, and shaming of the colleagues showed lowest percentage among three groups of the study with statistical significance difference.

Table 6 showed Safety Injection Checklist among nursing students, $18 \%$ of study group of first group were unsatisfied while $100 \%$ of $3^{r d}$ group showed satisfied practice followed by $2^{\text {nd }}$ group.

Table 4. Reason of injury of needle stick injury from student's point of view

\begin{tabular}{|c|c|c|c|c|c|c|c|c|}
\hline \multirow{2}{*}{ Variable } & \multicolumn{2}{|c|}{$1^{\text {st }}$ group $(N=50)$} & \multicolumn{2}{|c|}{$2^{\text {nd }}$ group $(N=50)$} & \multicolumn{2}{|c|}{$3^{\text {rd }}$ group $(N=50)$} & \multirow{2}{*}{$\chi^{2}$} & \multirow{2}{*}{$p$-value } \\
\hline & No & $\%$ & No & $\%$ & No & $\%$ & & \\
\hline Rush & 4 & $8 \%$ & 4 & $8 \%$ & 5 & $10 \%$ & \multirow{4}{*}{0.32} & \multirow{4}{*}{.999} \\
\hline Lack of experience & 6 & $12 \%$ & 5 & $10 \%$ & 6 & $12 \%$ & & \\
\hline Lack of assistant & 1 & $2 \%$ & 1 & $2 \%$ & 1 & $2 \%$ & & \\
\hline Excitement & 39 & $78 \%$ & 40 & $80 \%$ & 38 & $76 \%$ & & \\
\hline
\end{tabular}

Table 5. Reason for not reporting injury of needle stick

\begin{tabular}{|c|c|c|c|c|c|c|c|c|}
\hline \multirow{2}{*}{ Variable } & \multicolumn{2}{|c|}{$1^{\text {st }}$ group $(\mathrm{N}=50)$} & \multicolumn{2}{|c|}{$2^{\text {nd }}$ group $(N=50)$} & \multicolumn{2}{|c|}{$3^{\text {rd }}$ group $(N=50)$} & \multirow{2}{*}{$\chi^{2}$} & \multirow{2}{*}{$p$-value } \\
\hline & No & $\%$ & No & $\%$ & No & $\%$ & & \\
\hline Fear of stigmatization and discrimination & 7 & $14 \%$ & 3 & $6 \%$ & 8 & $16 \%$ & \multirow{6}{*}{18.04} & \multirow{6}{*}{.054} \\
\hline Lack of knowledge about reporting the injuries & 13 & $26 \%$ & 7 & $14 \%$ & 11 & $22 \%$ & & \\
\hline Heavy clinical work load & 5 & $10 \%$ & 2 & $4 \%$ & 5 & $10 \%$ & & \\
\hline Low risk of infection in the injured site & 4 & $8 \%$ & 3 & $6 \%$ & 3 & $6 \%$ & & \\
\hline Shaming of the colleagues & 4 & $8 \%$ & 0 & 0 & 1 & $2 \%$ & & \\
\hline Punishment and low grade during evaluation & 17 & $34 \%$ & 35 & $70 \%$ & 22 & $44 \%$ & & \\
\hline
\end{tabular}

Table 6. Safety injection checklist for among nursing students

\begin{tabular}{|c|c|c|c|c|c|c|c|c|}
\hline \multirow{2}{*}{ Variable } & \multicolumn{2}{|c|}{$1^{\text {st }}$ group $(\mathrm{N}=50)$} & \multicolumn{2}{|c|}{$2^{\text {nd }}$ group $(\mathrm{N}=50)$} & \multicolumn{2}{|c|}{$3^{\text {rd }}$ group $(\mathrm{N}=50)$} & \multirow{2}{*}{ Test of significance } & \multirow{2}{*}{$p$-value } \\
\hline & No & $\%$ & No & $\%$ & No & $\%$ & & \\
\hline Unsatisfied & 9 & 18.0 & 2 & 4.0 & 0 & 0.0 & \multirow{2}{*}{$\chi^{2}=13.14$} & \multirow{2}{*}{.001} \\
\hline Satisfied & 41 & 82.0 & 48 & 96 & 50 & 100.0 & & \\
\hline
\end{tabular}

\section{Discussion}

\subsection{Prevalence of needle stick injuries}

Needle stick injury is an important fundamental factor of poor injection safety practices by health workers. In the present study nearly $25 \%$ of academic students at three different setting of the study reported that they experienced needle stick injuries at least once during their training at clinical setting which is the study sample represented from three different academic students. This was in accordance with Amini et al. ${ }^{[11]}$ who reported that more than one third of the studied sample of students $(38 \%)$ had experienced needle stick injuries. In Egypt, more than two thirds of studied participants of nurses (62.3\%) reported needle stick injuries at least once. ${ }^{[12]}$

Published by Sciedu Press
Also, Anupriya \& Manivelan ${ }^{[13]}$ study illustrated that two thirds of the student nurses experienced needle stick injuries and this number increased among nursing students at the higher level. Also, it was reported in the study of Sharma et al. ${ }^{[9]}$ high prevalence $(61.5 \%)$ of sharps exposures among nursing students. The maximum range occurred during first year $(57.57 \%)$. From the researcher point of view; this increased percentage for exposure to injuries could be explained by needle stick injuries were increased by more exposure during training and decreased experience.

\subsection{Area of clinical setting}

The present study reported that injuries at the outpatient clinic and medical department represented high percentage, while the least percentage was at emergency department. 
Contrary this results, Anupriya $\&$ Manivelan ${ }^{[13]}$ reported that most of the needles stick injuries occurred in the emergency and the medical surgical units. And Akyol \& $\operatorname{Kargin}^{[14]}$ revealed that sharp and needle stick injury increased in the surgical (34.9\%) and intensive care units (37.9\%). While Memish et al. ${ }^{[1]}$ clarified that occurrence of needle stick injuries most commonly in the patient room/ward, emergency, the intensive care and critical care units. In the study of Yao et al. ${ }^{[15]}$ needle stick injuries occurred frequently by the students in medical and Gynecology \& Obstetrics wards. Cheung et al.' $\mathrm{s}^{[16]}$ study showed that the highest rate of needle stick injuries occurred in the emergency (30.8\%), and $(21.2 \%)$ in medical departments. This discrepancy of results may be due to the differentiation of area of student training areas.

\subsection{Mechanism of injury of needles}

The present study revealed that most injuries occurred during IV injection, followed by IM injection and recapping needle with no statistical significant difference. And half of these injuries occurred during use of needle during injection then during specific procedure as IV line. While after use but before disposal over half of three groups injured during bending or breaking by hand before disposal. In a study of Motaarefi et al. ${ }^{[17]}$ demonstrated that the risk for needles stick injuries significantly increased among those who usually or always did needle recapping in comparison to those who did not. On the same line, Anupriya \& Manivelan ${ }^{[13]}$ reported that most injuries reasoned for injection, as most students used to recap the needle after use. And around half of them didn't report the injuries. In the same consistent, Kohestani et al.'s study ${ }^{[18]}$ showed that the majority of needle stick injuries occurred during Venipuncture (40\%) and collecting blood samples $(21 \%)$ also two thirds of them were injured from needles at this stage. In Amini et al.'s ${ }^{[11]}$ study $64.2 \%$ of needle stick injuries occurred after the procedure and before get rid of the sharp object. All of that reports pointed to in adequate awareness of risk needle stick injuries and importance of preventive measures.

\subsection{Concerning reason of injury of needles stick from student's point of view}

The present study showed that the majority of students from all groups perceived that the reason of injury of needle sticks were excitement and lack of experience. On the same line; Amukugo et al. ${ }^{[4]}$ presented that needle stick injuries were caused by recapping needle, low experiences of clinical practice skills related to handling sharp objects. Also, Irmak et al. ${ }^{[16]}$ showed that more than half of studied group injured from a syringe needle and about one third injured by a glass item. Furthermore, injuries occurred most frequently dur- ing withdrawing a needle from resistant material, recapping needle and break up device or equipment. ${ }^{[14]}$ Jose et al. ${ }^{[19]}$ mentioned that $6.7 \%$ of nursing students were unaware of the prevention of needle stick injury practices. Out of which $28 \%$ of nursing students were exposed to needle stick injury before the procedure, $28 \%$ nursing students were exposed during the procedure and $42 \%$ nursing students were exposed after the procedure. $20 \%$ nursing students faced problems in safe handling and disposal of needles. In Liyanage et al.' ${ }^{[20]}$ study, the majority of needle stick injuries among studied sample occurred during suturing; venipuncture and recapping needles represented the least percentage of the injuries. All of that recommended education and training about preventive measures of needle stick injuries.

\subsection{Considering causes for not reporting needle stick in- jury}

The present study showed that fear of punishment and low grade during evaluation was the most common cause for non-reporting injury of needle stick among three groups followed by lack of knowledge about reporting the injuries. It was found that (54.54\%) of needle stick injuries were not reported. Among injury exposures, ${ }^{[8]}$ in a study of Cui et al. ${ }^{[21]}$ sharp injuries among the studied subjects were commonly underreported. Also, the possible reasons for needle stick injuries from Sharma's ${ }^{[22]}$ study; the greater part of injuries (48\%) occurred after needle use but before disposal and only $6.8 \%$ during disposal of the needle when recapping needle was observed to be the most frequent procedure. On the same line, Jahangiri et al. ${ }^{[8]}$ revealed that the most common leading cause to needle stick injuries was recapping needles $(41.4 \%)$. The percentage of non-reporting needle stick injuries was $60.2 \%$ and the major reasons for this were heavy clinical workload and perception of low risk of infection. Also, Onyemocho et al. ${ }^{[23]}$ stating that the reasons for needle stick injuries include working under the pressure. Moreover, the most important findings, majority of the studied sample did not report needle stick injuries. ${ }^{[14]}$

\subsection{Regarding to injection practices among nursing stu- dents}

The present study showed $18 \%$ of first group represent unsatisfied practice while $100 \%$ of 3rd group showed satisfied practice followed by 2 nd group. Concerning this result, Gyawali et al. ${ }^{[24]}$ found that more than half $(65.9 \%)$ of the studied group had good practice of injection safety, nearly one third of the respondents fairly practiced injection safety, while only $6.8 \%$ had poor practice of injection safety. Furthermore, Isara et al.' ${ }^{[25]}$ study showed that the respondents around half had a better degree of practice of safety injection and less than half of them have a good and excellent practice 
of injection safety respectively. While Kulkarni et al. ${ }^{[26]}$ reported that majority of the studied group were not aware of the meaning of safety injection. $71.42 \%$ of the studied group didn't know immediate action in case of accidental injury, While $40 \%$ among studied group didn't aware about risk of unsafe injection. From researcher point of view; although of nearly high level of good or satisfied practice but it is not accepted to threat safety even with low percentage so continuous awareness and frequent evaluation at suitable interval are a necessity for our safety.

\section{Conclusion}

The study concluded that increasing the awareness about the importance of reporting needle stick injuries is cardinal intervention to take adequate preventive measures for safety and continuous training and awareness program on injection safety to all the student nurses is a necessity for reducing the unsafe practices.

\section{Recommendations}

- It is important to develop a good effective reporting system among newly graduated nurses when they work in a real situation.

- It is suggested to provide adequate practical skills in order to develop clinical competence in nursing and to follow protocol on how to safely handle needles.

\section{ACKNOWLedgements}

I'm grateful to the nursing students who completed the questionnaire and to clinical instructors and teachers from the faculty of nursing and the School of Nursing, for their organizational assistance and assistance with data collection.

\section{Conflicts of InTEREST Disclosure}

The author declares no conflicts of interest.

\section{REFERENCES}

[1] Memish ZA, Assiri AM, Eldalatony MM, et al. Risk analysis of needle stick and sharp object injuries among health care workers in a tertiary care hospital (Saudi Arabia). Journal of Epidemiology and Global Health. 2013; 3(3): 123-129. PMid:23932054. https://doi.org/10.1016/j.jegh.2013.03.004

[2] Zhang X, Chen Y, Li Y, et al. Needlestick and Sharps Injuries Among Nursing Students in Nanjing, China. Workplace Health and Safety. 2018; 66(6): 276-284. PMid:29073827. https ://doi .org/10.1 $177 / 2165079917732799$

[3] Nawafleh HA, Abozead SE, Al Momani MM, et al. Investigating needle stick injuries: Incidence, knowledge and perception among South Jordanian nursing students. Journal of Nursing Education and Practice. 2018; 8(4): 59. https : //doi .org/10.5430/jnep.v8n4p59

[4] Amukugo HJ, Hn Shitokelwa T, Nuuyoma V. Experiences of University of Namibia nursing students on needle stick injuries: A qualitative study. J Nurs Res Pract. 2018; 2.

[5] Kebede A, Gerensea H. Prevalence of needle stick injury and its associated factors among nurses working in public hospitals of Dessie town, Northeast Ethiopia, 2016. BMC Res Notes [Internet]. 2018; 11(1): 1-6. https ://doi.org/10.1186/s13104-018-3529-9

[6] Massaro T, Cavone D, Orlando G, et al. Needlestick and sharps injuries among nursing students: an emerging occupational risk. G. Ital. Med. Lav. Ergon. 2007; 29(3 Suppl): 631-632. PMid:18409876. Available from: http://www.ncbi.nlm.nih.gov/pubmed/1840 9876

[7] Irmak Z, Baybuga MS. Needlestick and sharps injuries among Turkish nursing students: A cross-sectional study. International Journal of Nursing Practice. 2011; 17(2): 151-157. https : //doi .org/10 $.1111 / \mathrm{j} .1440-172 \mathrm{X} .2011 .01920 . \mathrm{x}$

[8] Goel V, Kumar D, Lingaiah R, et al. Occurrence of needlestick and injuries among health-care workers of a Tertiary Care Teaching Hospital in north India. J Lab Physicians. 2017; 9: 20-5. PMid:28042212. https://doi.org/10.4103/0974-2727.187917
[9] Sharma R, Bhatt A, Painuly D, et al. Original article occurrence and knowledge about needle stick injury. 2015; 27(2): 430-433.

[10] Jahangiri M, Rostamabadi A, Hoboubi N, et al. Needle Stick Injuries and their Related Safety Measures among Nurses in a University Hospital, Shiraz, Iran. Safety and Health at Work. 2016; 7(1): 72-77. PMid:27014494. https ://doi.org/10.1016/j.shaw. 2015.07 .006

[11] Amini R, Soltanian AR, Ebrahimkhani A, et al. Investigating the use of safe injection guidelines after needle stick and sharp instruments injuries in Nursing \& Midwifery students of Hamadan University of Iran. E3 Journal of Medical Research. 2016; 5(1): 8-014.

[12] Hanafi M, Mohamed A, Kassem M, et al. Needlestick injuries among health care workers of University of Alexandria Hospitals. East Mediterr Health J. 2011; 17: 26e35.

[13] Anupriya A, Manivelan S. KAP study on the assessment of needlestick injuries and occupational safety among health-care workers. International Journal of Medical Science and Public Health. 2014; 4(3): 342. https://doi.org/10.5455/ijmsph.2015.1810201464

[14] Akyol AD, Kargın C. Needle stick and sharp injuries among nurses. Global Journal of Nursing \& Foreneedle Stick Injuries Studies. 2016; 1(4): 1-5. https://doi .org/10.4172/2572-0899.1000109

[15] Yao WX, Wu YL, Yang B, et al. Occupational safety training and education for needle stick injuries among nursing students in China: intervention study. Nurse Education Today. 2013; 33(8): 834-7. PMid:22405342. https://doi.org/10.1016/j.nedt.2012.02 .004

[16] Cheung K, Ho SC, Ching SSY, et al. Analysis of needle stick injuries among nursing students in Hong Kong. Accident Analysis \& Prevention. 2010; 42(6): 1744-50. PMid:20728625. https : //doi.org/10.1016/j.aap.2010.04.015

[17] Motaarefi H, Mahmoudi H, Mohammadi E, et al. Factors associated with needlestick injuries in health care occupations: A systematic review. Journal of Clinical and Diagnostic Research. 2016; 10(8): IE01IE04. https://doi.org/10.7860/JCDR/2016/17973.8221 
[18] Kohestani H, Baghcheghi N, Rezai K. Blood contaminated needle stick/sharp objects injuries and exposure to patients' body fluid in medical emergencies students. Iranian Journal of Critical Care Nursing. 2010; 3(2): 57-62.

[19] Jose JA, Sheeja A, Singh SK, et al. Effectiveness of Structured Teaching Programmes on Practices in Prevention of Needle Sticks Injury. J Nur Today. 2016; 1(2): 11-20.

[20] Liyanage I, Caldera T, Rwma R, et al. Sharps injuries among medical students in the faculty of medicine, Colombo, Sri Lanka. International Journal of Occupational Medicine and Environmental Health. 2012. PMid:22729497. https://doi.org/10.2478/s1 3382-012-0036-4

[21] Cui Z, Zhu J, Zhang X, et al. Sharp injuries: A cross-sectional study among health care workers in a provincial teaching hospital in China. Environmental Health and Preventive Medicine. 2018; 23(1): 17. PMid:29316884. https ://doi.org/10.1186/s12199-017-0 691-y

[22] Sharma S. Needle Stick Injury and Inadequate Post Exposure Practices Among Health Care Workers of a Tertiary Care Centre in rural India. International Journal of Collaborative Research on Internal Medicine \& Public Health. 2012; 4(5): 638-648.
[23] Onyemocho A, Joshua IA, Enokela OP. Knowledge and practice of injection safety among nurses of Nigerian Prison Service Health Facilities in Kaduna State. American Journal of Public Health Research. 2013; 1(7): 171-176. https://doi.org/10.12691/ajphr-1-7 $-5$

[24] Gyawali S, Rathore DS, Kc B, et al. Study of status of safe injection practice and knowledge regarding injection safety among primary health care workers in Baglung district, western Nepal. BMC International Health and Human Rights. 2013. PMid:23286907. https : //doi.org/10.1186/1472-698X-13-3

[25] Isara A, Omorogbe V, Omuemu V. Injection safety practices among nursing staff of mission hospitals in Benin City, Nigeria. Annals of African Medicine. 2012; 11(1): 36. PMid:22199046. https: //doi.org/10.4103/1596-3519.91020

[26] Kulkarni RS, Giri PA, Gangwal PR. Injection Safety: Knowledge and Practices among Nursing Personnel in Tertiary Care Teaching Hospital of Marathwada Region of Maharashtra, India. Arch Community Med Public Health. 2016; 2(1): 018-021. https: //doi.org/10.17352/2455-5479.000011 